\title{
Genetic Variation in the Ontario Neurodegenerative Disease Research Initiative
}

\author{
Allison A. Dilliott, Emily C. Evans, Sali M.K. Farhan, Mahdi Ghani, Christine Sato, \\ Ming Zhang, Adam D. McIntyre, Henian Cao, Lemuel Racacho, John F. Robinson, \\ Michael J. Strong, Mario Masellis, Dennis E. Bulman, Ekaterina Rogaeva, \\ Sandra E. Black, Elizabeth Finger, Andrew Frank, Morris Freedman, \\ Ayman Hassan, Anthony Lang, Christen L. Shoesmith, Richard H. Swartz, \\ David Tang-Wai, Maria Carmela Tartaglia, John Turnbull, Lorne Zinman, \\ the ONDRI Investigators, Robert A. Hegele
}

\begin{abstract}
Background/Objective: Apolipoprotein E (APOE) E4 is the main genetic risk factor for Alzheimer's disease (AD). Due to the consistent association, there is interest as to whether E4 influences the risk of other neurodegenerative diseases. Further, there is a constant search for other genetic biomarkers contributing to these phenotypes, such as microtubule-associated protein tau (MAPT) haplotypes. Here, participants from the Ontario Neurodegenerative Disease Research Initiative were genotyped to investigate whether the APOE E4 allele or MAPT H1 haplotype are associated with five neurodegenerative diseases: (1) AD and mild cognitive impairment (MCI), (2) amyotrophic lateral sclerosis, (3) frontotemporal dementia (FTD), (4) Parkinson's disease, and (5) vascular cognitive impairment. Methods: Genotypes were defined for their respective APOE allele and MAPT haplotype calls for each participant, and logistic regression analyses were performed to identify the associations with the presentations of neurodegenerative diseases. Results: Our work confirmed the association of the E4 allele with a dose-dependent increased presentation of AD, and an association between the E4 allele alone and MCI; however, the other four diseases were not associated with E4. Further, the APOE E2 allele was associated with decreased presentation of both AD and MCI. No associations were identified between MAPT haplotype and the neurodegenerative disease cohorts; but following subtyping of the FTD cohort, the H1 haplotype was significantly associated with progressive supranuclear palsy. Conclusion: This is the first study to concurrently analyze the association of $A P O E$ isoforms and MAPT haplotypes with five neurodegenerative diseases using consistent enrollment criteria and broad phenotypic analysis.
\end{abstract}

RÉSUMÉ: Étude de variance génétique dans le cadre de l'initiative de recherche sur les maladies neurodégénératives en Ontario. Contexte/ Objectif : L'apolipoprotéine E4 (ApoE4) constitue le principal facteur de risque génétique de la maladie d'Alzheimer. En raison de cette association systématique, il existe un intérêt certain à savoir dans quelle mesure cette classe d'apolipoprotéines peut influencer le risque d'autres maladies neurodégénératives. En outre, le milieu de la recherche n'a de cesse d'identifier d'autres biomarqueurs génétiques, par exemple les haplotypes H1 de la protéine tau associée aux microtubules, qui contribuent à certains phénotypes, Dans le cadre de cette étude, des participants à l'initiative de recherche sur les maladies neurodégénératives en Ontario ont été « génotypés » afin de déterminer si l'ApoE4 ou l'haplotype H1 mentionné ci-dessus peuvent être associés à cinq maladies neurodégénératives : 1) la maladie d'Alzheimer et d'autres troubles cognitifs légers ; 2) la sclérose latérale amyotrophique ; 3) la démence fronto-temporale ; 4) la maladie de Parkinson ; 5) et finalement les déficits cognitifs d'origine vasculaire. Méthodes : Pour chaque participant, la

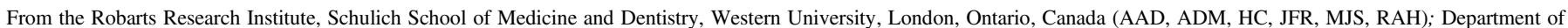

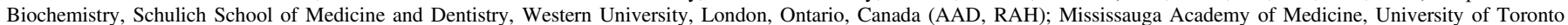

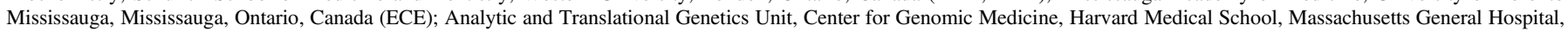



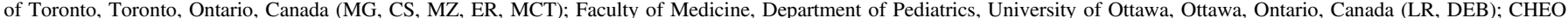

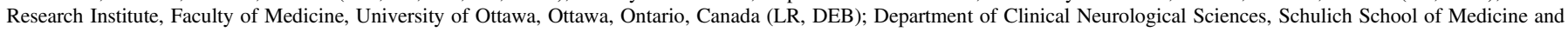

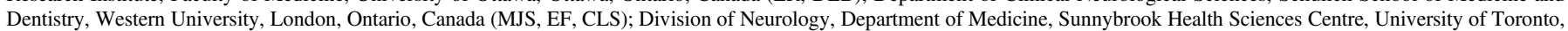

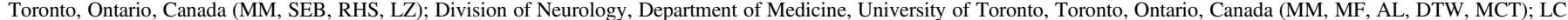



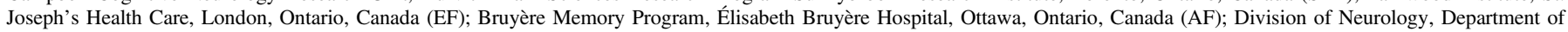

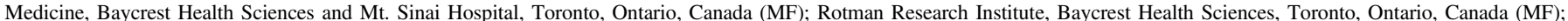

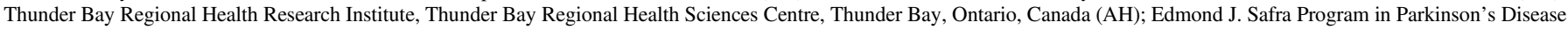


Ontario, Canada (DTW); Andrew Bruce Douglas Chair in Neurology, Faculty of Health Sciences, McMaster University, Hamilton, Ontario, Canada (JT)

Received March 1, 2019. Final Revisions Submitted May 30, 2019. Date of Acceptance June 1, 2019.

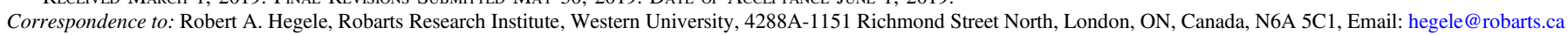


cartographie des génotypes a été établie en fonction de leur ApoE4 respectif et de la présence d'haplotypes H1 de la protéine tau associée aux microtubules. Des analyses de régression logistique ont été ensuite effectuées dans le but d'identifier de possibles liens avec ces maladies neurodégénératives. Résultats : Nos travaux ont confirmé l'association entre l'ApoE4 et une plus grande occurrence de cas d'Alzheimer, et ce, en tenant compte de l'effet d'une dose de médicament. Ils ont aussi montré une association entre la seule ApoE4 et des troubles cognitifs légers. Cela dit, il convient de préciser que les quatre autres maladies n'ont pas été associées à cet allèle. Plus encore, nous avons trouvé que l'allèle E2 de l'apolipoprotéine était associé à une occurrence plus faible de cas d'Alzheimer et de troubles cognitifs légers. Fait à souligner, aucune association n'a été détectée entre l'haplotype H1 de la protéine tau associée aux microtubules et nos cohortes atteintes de maladies neurodégénératives. Toutefois, à la suite du sous-typage de la cohorte de participants atteints de démence fronto-temporale, il s'est avéré que l'haplotype H1 était associé de façon notable à la paralysie supranucléaire progressive. Conclusion : Il s'agit de la première étude à analyser simultanément, au moyen de critères de participation cohérents et d'une analyse phénotypique élargie, les associations entre les isoformes de l'ApoE, l'haplotype H1 de la protéine tau associée aux microtubules et cinq maladies neurodégénératives.

Keywords: Alzheimer's disease, Neurodegenerative disease, APOE, MAPT

Abbreviations: $\quad \mathrm{AD}=$ Alzheimer's disease, $\mathrm{ALS}=$ amyotrophic lateral sclerosis, $A P O E=$ apolipoprotein $\mathrm{E}, \mathrm{FTD}=$ frontotemporal dementia, $M A P T=$ microtubule-associated protein tau, $\mathrm{MCI}=$ mild cognitive impairment, ONDRI $=$ Ontario Neurodegenerative Disease Research Initiative, $\mathrm{PD}=$ Parkinson's disease, $\mathrm{PSP}=$ progressive supranuclear palsy, $\mathrm{SNP}=$ single nucleotide polymorphism, VCI = vascular cognitive impairment

doi:10.1017/cjn.2019.228

Can J Neurol Sci. 2019; 46: 491-498

\section{INTRODUCTION}

With the aging of populations, the burden of neurodegenerative diseases is increasing, and substantial effort is directed toward identification of genetic biomarkers with the objective of improved disease prediction and the long-term goal of discovering therapeutic targets. In particular, molecular genetics efforts have focused on identifying common single nucleotide polymorphisms (SNPs) that contribute to disease risk. ${ }^{1-3}$ Although these types of markers usually account for only a small proportion of disease risk, two closely linked common SNPs on chromosome 19 have been identified to jointly impart a relatively large effect on the risk of a particular neurodegenerative phenotype, namely, the apolipoprotein E (APOE) E4 allele and Alzheimer's disease (AD). ${ }^{4}$

APOE is found in chylomicrons, very-low-density lipoproteins, intermediate-density lipoproteins, and high-density lipoproteins; it provides structural support to these particles and also governs the catabolism of triglyceride-rich lipoproteins through its role as a receptor ligand. Importantly, APOE is the principal cholesterol carrier in the brain. ${ }^{5}$ There are three common protein isoforms of APOE - E2, E3, and E4 - historically designated based on protein mobility in isoelectrophoretic focusing gels. ${ }^{6}$ At the DNA level, these three isoforms are encoded by two nonsynonymous SNPs within the APOE gene, occurring at amino acid positions 130 and 176 (also numbered as 112 and 158 , respectively, if the pro-peptide sequence is excluded), and each involving cysteine or arginine as alternate residues. ${ }^{7}$ The E4 allele, which has arginine at both positions 130 and 176, is the most common genetic risk factor for the development of late onset $\mathrm{AD}$ and contributes to disease risk in a dose-dependent manner. ${ }^{8}$ Meta-analyses show that one and two copies of the E4 allele raise $\mathrm{AD}$ risk by $\sim 3$ - to 4 - and $\sim 12$-fold, respectively. ${ }^{9,10}$ Due to the replicated high-risk association from several metaanalyses of $\mathrm{AD}$ and $A P O E,{ }^{8,11,12}$ researchers have attempted to determine whether the $\mathrm{E} 4$ allele is also associated with other neurodegenerative diseases, including amyotrophic lateral sclerosis (ALS), ${ }^{13,14}$ frontotemporal dementia (FTD), ${ }^{15,16}$ Parkinson's disease (PD), ${ }^{17-19}$ and vascular cognitive impairment (VCI), ${ }^{20-22}$ so far with mixed and inconsistent results.

Another gene less consistently associated with AD risk is the microtubule-associated protein tau gene (MAPT) that encodes the protein tau. ${ }^{23}$ It remains to be established whether MAPT is associated with other neurodegenerative diseases. Within the MAPT gene, an ancestral inversion of $\sim 900 \mathrm{~kb}$ has resulted in two distinct haplotypes, $\mathrm{H} 1$ and $\mathrm{H} 2$, and creates a large region of linkage disequilibrium. Apart from the few associations found between $\mathrm{H} 1$ MAPT and $\mathrm{AD}$, there is debate as to whether the haplotype is associated with $\mathrm{PD}^{24}$ and with the FTD subtype progressive supranuclear palsy (PSP). ${ }^{25,26}$

The Ontario Neurodegenerative Disease Research Initiative (ONDRI) is a multi-platform, provincial-wide, observational cohort study aiming to characterize multiple attributes of five neurodegenerative diseases, namely, (1) AD and mild cognitive impairment (AD/MCI), (2) ALS, (3) FTD, (4) PD, and (5) VCI. ${ }^{27}$ In addition to genomic analysis, ONDRI incorporates a comprehensive phenotypic assessment on each participant. The large data set, combined with the consistent enrollment criteria, allows for the unique opportunity to assess the association of $A P O E$ genotype and $M A P T$ haplotype across the respective neurodegeneration phenotypes. Here we aim to replicate the known associations of the $A P O E \mathrm{E} 4$ allele, $A P O E \mathrm{E} 4 / 4$ genotype, and MAPT H1 haplotype with $\mathrm{AD}$, in addition to assessing whether APOE E4 and MAPT H1 confer risk to ALS, FTD, PD, and VCI within the ONDRI cohort.

\section{Methods}

Blood samples were collected from 519 ONDRI participants after informed consent was obtained, in accordance with the Research Ethics Boards at Hamilton General Hospital (Hamilton, Ontario, Canada); McMaster (Hamilton, Ontario, Canada); Parkwood Hospital (London, Ontario, Canada); London Health Sciences Centre (London, Ontario, Canada); The Ottawa Hospital 
Table 1: Demographics of the 519 ONDRI participants and 189 controls genotyped for $A P O E$ and haplotyped for $M A P T$

\begin{tabular}{l|c|c|c|c|c|c|c}
\hline & ONDRI & AD/MCI & ALS & FTD & PD & VCI & Controls \\
\hline Cases & 519 & 126 & 40 & 53 & 139 & 161 & 189 \\
\hline $\begin{array}{l}\text { Mean Age } \\
\text { (years } \pm \text { sd) }\end{array}$ & $68.6 \pm 7.7$ & $71.0 \pm 8.2$ & $62.0 \pm 8.7$ & $67.8 \pm 7.0$ & $67.9 \pm 6.3$ & $69.2 \pm 7.4$ & $74.0 \pm 8.2$ \\
\hline Min. Age (years) & 40.1 & 53.4 & 40.1 & 49.7 & 55.1 & 54.9 & 48.0 \\
\hline Max. Age (years) & 87.8 & 87.8 & 77.2 & 80.9 & 85.9 & 85.4 & 92.0 \\
\hline Male: Female & $345: 174$ & $69: 57$ & $24: 16$ & $34: 19$ & $108: 31$ & $110: 51$ & $77: 112$ \\
\hline
\end{tabular}

$\mathrm{AD} / \mathrm{MCI}=$ Alzheimer's disease/mild cognitive impairment; ALS = amyotrophic lateral sclerosis; $A P O E=$ apolipoprotein $\mathrm{E}$ gene; FTD = frontotemporal dementia; $M A P T=$ microtubule-associated protein tau gene; Max = maximum; Min = minimum; ONDRI = Ontario Neurodegenerative Disease Research Initiative; $\mathrm{PD}=$ Parkinson's disease; $\mathrm{sd}=$ standard deviation; $\mathrm{VCI}=$ vascular cognitive impairment.

Table 2: $A P O E$ allele and genotype frequencies in 519 ONDRI participants and 189 controls. All study participants were genotyped using both the ONDRISeq panel and TaqMan allelic discrimination assay

\begin{tabular}{|c|c|c|c|c|c|c|c|c|c|}
\hline & \multicolumn{6}{|c|}{ APOE Genotype [n (\%)] } & \multicolumn{3}{|c|}{ APOE Alleles [n (\%)] } \\
\hline & $\mathrm{E} 2 / 2$ & $\mathbf{E} 3 / 2$ & $\mathbf{E} 4 / 2$ & $\mathbf{E} 3 / \mathbf{3}$ & $\mathbf{E} 4 / 3$ & E4/4 & E2 & E3 & E4 \\
\hline $\mathrm{AD} / \mathrm{MCI}$ & 0 & $5(4.0)$ & $1(0.8)$ & $59(46.8)$ & $43(34.1)$ & $18(14.3)$ & $6(2.4)$ & $166(65.9)$ & $80(31.7)$ \\
\hline ALS & 0 & $6(15.0)$ & 0 & $21(52.5)$ & $12(30.0)$ & $1(2.5)$ & $6(7.5)$ & $60(75.0)$ & $14(17.5)$ \\
\hline FTD & $1(1.9)$ & $6(11.3)$ & 0 & $26(49.0)$ & $18(34.0)$ & $2(3.8)$ & $8(7.5)$ & $76(71.7)$ & $22(20.8)$ \\
\hline PD & $1(0.7)$ & $19(13.7)$ & $3(2.2)$ & $86(67.9)$ & $28(20.1)$ & $2(1.4)$ & $24(8.6)$ & $219(78.8)$ & $35(12.6)$ \\
\hline VCI & 0 & $21(13.0)$ & $2(1.2)$ & $100(62.1)$ & $34(21.1)$ & $4(2.5)$ & $23(7.1)$ & $255(79.2)$ & $44(13.7)$ \\
\hline Controls & $2(1.1)$ & $29(15.3)$ & $6(3.2)$ & 110 & 35 (18.6) & $7(3.7)$ & 39 (10.3) & $284(75.1)$ & $55(14.6)$ \\
\hline
\end{tabular}

$\mathrm{AD} / \mathrm{MCI}=$ Alzheimer's disease/mild cognitive impairment; ALS = amyotrophic lateral sclerosis; $A P O E=$ apolipoprotein $\mathrm{E}$ gene; FTD = frontotemporal dementia; ONDRI = Ontario Neurodegenerative Disease Research Initiative; PD = Parkinson's disease; VCI = vascular cognitive impairment.

(Ottawa, Ontario, Canada); University Health NetworkElizabeth Bruyère Hospital (Ottawa, Ontario, Canada); Baycrest Centre for Geriatric Care (Toronto, Ontario, Canada); Centre for Addiction and Mental Health (Toronto, Ontario, Canada); St Michael's Hospital (Toronto, Ontario, Canada); Sunnybrook Health Sciences Centre (Toronto, Ontario, Canada); and Toronto Western Hospital (Toronto, Ontario, Canada). Formal diagnoses and demographic data were obtained by participants' clinicians upon enrollment in the study, in accordance with ONDRI standard operating protocols. $^{27}$

Genomic DNA was isolated from blood samples collected from each participant, as described previously. ${ }^{28}$ DNA samples were also obtained from 189 cognitively normal controls from the GenADA study. ${ }^{29}$ All samples underwent targeted next-generation sequencing using the ONDRISeq neurodegenerative disease gene panel. Full methodology of DNA isolation, sequencing with the ONDRISeq panel, ${ }^{28}$ and raw sequencing data processing were previously described. ${ }^{30}$

Allele calls for the APOE risk alleles rs429358(CT): p.Cys130Arg and rs7412(CT):p.Arg176Cys were extracted from the ONDRISeq data files and mapped to their respective $A P O E$ genotype for each participant using a customized Annotate Variation $^{31}$ script. Allele calls and mapped genotypes were validated with TaqMan allelic discrimination assay, ${ }^{32}$ as previously described. ${ }^{28}$

TaqMan was also used to determine the tau haplotype of the ONDRI participants and control samples. DNA samples were genotyped for the intronic SNP rs1800547, which is not covered by the ONDRISeq panel. Based on a region of linkage disequilibrium, allele calls were mapped to their respective MAPT haplotype. $^{33}$

Statistical analyses were performed using SAS v9.4 (SAS Institute, Cary, NC, USA). The Wilcoxon Mann-Whitney $U$ test was utilized to determine the difference between the ages of the control cohort compared to the five disease cohorts of interest. Chisquare analyses were used to determine the difference between the control cohort and disease cohorts' male-female ratios. Odds ratios (ORs) and confidence intervals (CIs) were obtained using logistic regression, adjusting for participants' age and sex.

\section{RESUlts}

Table 1 displays the demographics of the 519 ONDRI participants included in this study as well as the cognitively normal controls. Of the ONDRI participants, $83.0 \%$ self-reported their ethnicity as Caucasian. The ALS cohort had the lowest mean age (62.0 \pm 8.7 years), and the control cohort had the highest mean age (74.0 \pm 8.2 years), which was significantly different from the mean age of the five ONDRI disease cohorts $\left(P<1.0 \times 10^{-4}\right)$. Additionally, the male-female ratio of the control cohort was significantly different from that of the overall ONDRI cohort $\left(P<1.0 \times 10^{-4}\right)$.

Calls of the $A P O E$ alleles were obtained using the ONDRISeq panel and validated using the TaqMan allelic discrimination assay with $100 \%$ concordance. Allele and genotype frequencies were calculated for the five neurodegenerative disease cohorts and the controls (Table 2). As expected, the AD/MCI cohort 

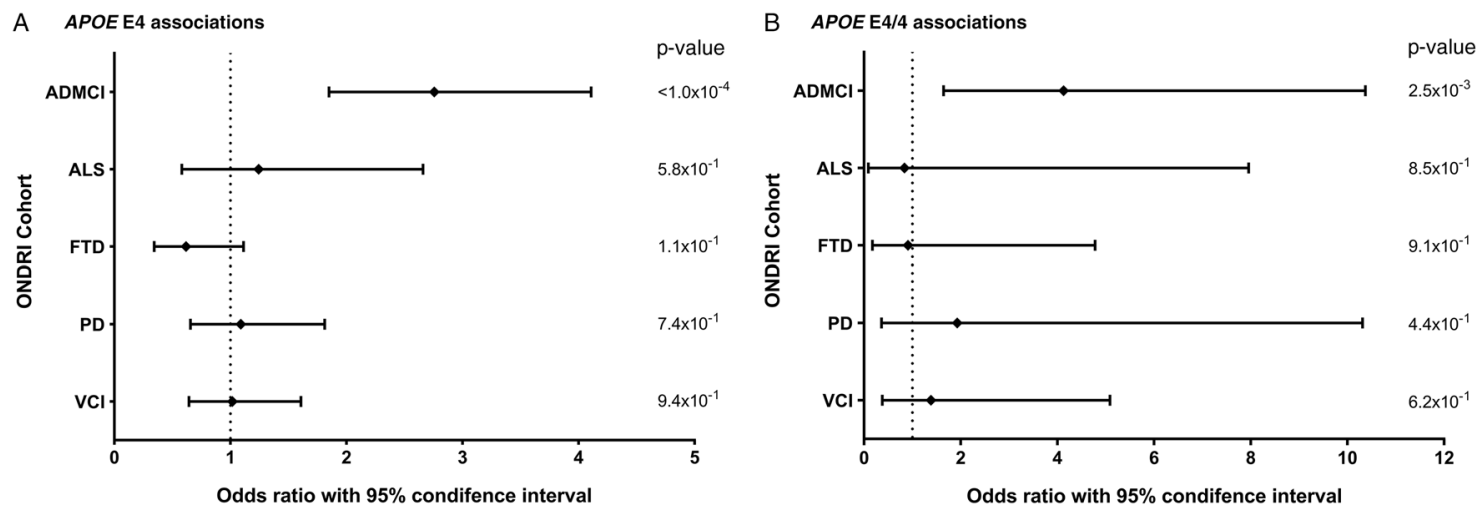

Figure 1: Forest plots of the relationship between APOE and risk of each of the diseases encompassed by ONDRI. Logistic regressions adjusting for participant age and sex analyzed the APOE E4 allele and E4/4 genotype status of the ONDRI cohorts when compared to controls. (A) Forest plot of the APOE E4 allele and associated risk of each ONDRI disease cohort. (B) Forest plot of the APOE E4/4 genotype and associated risk of each ONDRI disease cohort.

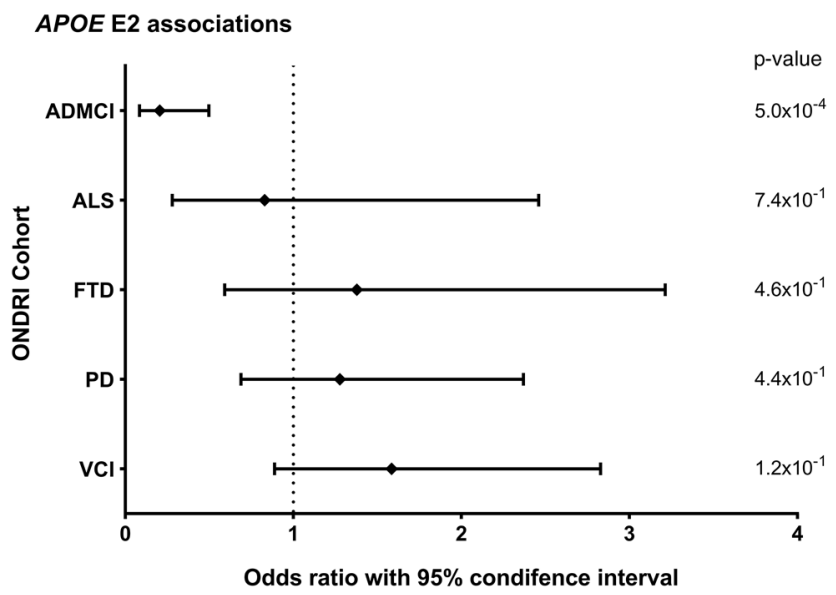

Figure 2: Forest plot of the relationship between the APOE E2 allele and risk of each of the diseases encompassed by ONDRI. Logistic regressions adjusting for participant age and sex analyzed the APOE E2 allele status of the ONDRI cohorts when compared to controls.

displayed the highest $A P O E$ E4 allele frequency $(31.7 \%)$ and E4/4 genotype frequency (14.3\%), compared to $14.6 \%$ and $3.7 \%$, respectively, in controls. The AD/MCI cohort also displayed the lowest $A P O E$ E2 allele frequency (2.4\%), compared to $10.3 \%$ in controls. The lowest $A P O E \mathrm{E} 4$ allele and E4/4 genotype frequencies were observed in the PD cohort $(12.6 \%$ and $1.4 \%$, respectively), differing marginally from the respective frequencies in controls.

Allele and genotype calls were compared between each ONDRI disease cohort and the control cohort, while adjusting for both age and sex of participants (Figure 1A and 1B). The E4 allele was significantly associated with increased presentation of AD/MCI compared to controls $(\mathrm{OR}=2.76,95 \% \mathrm{CI}=1.85-4.11$, $P<1.0 \times 10^{-4}$ ). Similarly, the E4/4 genotype significantly increased the presentation of $\mathrm{AD} / \mathrm{MCI}$ when compared to controls $\left(\mathrm{OR}=4.13,95 \% \mathrm{CI}=1.64-10.37, \mathrm{P}=2.5 \times 10^{-3}\right)$. As expected, the E2 allele was associated with a significantly decreased presentation of $\mathrm{AD} / \mathrm{MCI}$ when compared to controls after adjusting for age and sex $\left(\mathrm{OR}=0.21,95 \% \mathrm{CI}=0.08-0.50, P=5.0 \times 10^{-4}\right.$; Figure 2$)$.
No association with $A P O E$ was found with the other four phenotypes in the ONDRI data set.

The AD/MCI cohort was split into participants presenting with $\mathrm{AD}(\mathrm{n}=41)$ and those presenting with MCI $(\mathrm{n}=85)$ and $A P O E$ analyses were repeated. The $\mathrm{AD}$ and MCI subcohorts displayed E4 allele frequencies of $46.3 \%$ and $24.7 \%$ and E4/4 genotype frequencies of $26.8 \%$ and $8.2 \%$, respectively. Indeed, the E4 allele was significantly associated with presentation of both $\mathrm{AD}$ and $\mathrm{MCI}$ compared to the controls $(\mathrm{OR}=5.24,95 \%$ $\mathrm{CI}=3.07-8.92, P<1.0 \times 10^{-4}$ and $\mathrm{OR}=1.94,95 \% \mathrm{CI}=1.22-3.07$, $P=4.9 \times 10^{-3}$, respectively), and the E2 allele was significantly associated with decreased presentation of both $\mathrm{AD}$ and MCI compared to the controls $(\mathrm{OR}=0.10,95 \% \quad \mathrm{CI}=0.01-0.77$, $P=0.0268$ and $\mathrm{OR}=0.26,95 \% \mathrm{CI}=0.10-0.68, P=5.8 \times 10^{-3}$, respectively). The E4/4 genotype was also significantly associated with increased presentation of $\mathrm{AD}(\mathrm{OR}=10.36$, 95\% CI= $\left.3.55-30.19, P<1.0 \times 10^{-4}\right)$; however, the genotype was not significantly associated with the presentation of MCI.

Allele calls of the intronic MAPT variant, rs1800547, were mapped to their respective MAPT haplotype for each DNA sample. The ALS cohort had the highest frequencies of $\mathrm{H} 1$ haplotype and $\mathrm{H} 1 / \mathrm{H} 1$ diplotype $(87.5 \%$ and $75.0 \%$, respectively), whereas the FTD cohort displayed the lowest frequencies $(75.5 \%$ and $60.4 \%$, respectively; Table 3 ). There were no significant associations found between MAPT and any of the disease phenotypes in ONDRI when compared to controls following adjustment for both age and sex.

Due to its previous associations with the PSP subtype of FTD, the FTD cohort was split into its respective subtypes, including behavioral variant FTD (bvFTD; $n=22$ ), corticobasal syndrome (CBS; $n=3$ ), progressive non-fluent aphasia (PNFA; n=8), PSP $(n=15)$, and semantic dementia $(\mathrm{SD} ; \mathrm{n}=5)$, and MAPT analyses were repeated. Interestingly, the SD subcohort displayed the greatest MAPT H1 haplotype frequency and the CBS subcohort displayed the lowest, at $90.0 \%$ and $50.0 \%$, respectively. Similarly, the SD subcohort, along with the PSP subcohort, displayed the greatest $\mathrm{H} 1 \mathrm{H} 1$ diplotype frequency of $80.0 \%$, while the CBS subcohort displayed the lowest of $33.3 \%$. We also observed that the $\mathrm{H} 1$ haplotype was significantly associated with increased PSP prevalence $\left(\mathrm{OR}=7.46,95 \% \mathrm{CI}=2.39-23.29, P=5.0 \times 10^{-4}\right)$ following adjustment for age and sex; however, the $\mathrm{H} 1 \mathrm{H} 1$ diplotype 


\begin{abstract}
Table 3: MAPT haplotype and diplotype frequencies in 519 ONDRI participants and 189 controls. All study participants were genotyped for the intronic SNP rs1800547 using TaqMan allelic discrimination assay and results were mapped to their respective haplotype
\end{abstract}

\begin{tabular}{|c|c|c|c|c|c|}
\hline & \multicolumn{2}{|c|}{ MAPT Haplotype [n (\%)] } & \multicolumn{3}{|c|}{ MAPT Diplotype [n (\%)] } \\
\hline & H1 & H2 & H1/H1 & H1/H2 & $\mathrm{H} 2 / \mathrm{H} 2$ \\
\hline $\mathrm{AD} / \mathrm{MCI}$ & $200(79.4)$ & $52(20.6)$ & $75(59.5)$ & $50(39.7)$ & $1(0.8)$ \\
\hline ALS & $70(87.5)$ & $10(12.5)$ & $30(75.0)$ & $10(25.0)$ & 0 \\
\hline FTD & $80(75.5)$ & $26(24.5)$ & $32(60.4)$ & $16(30.2)$ & $5(9.4)$ \\
\hline PD & $227(81.7)$ & $51(18.3)$ & $93(66.9)$ & $41(29.5)$ & $5(3.6)$ \\
\hline VCI & $264(82.0)$ & $58(18.0)$ & $108(67.1)$ & $48(29.8)$ & $5(3.1)$ \\
\hline Controls & 293 (77.5) & $85(22.5)$ & 111 & $71(37.6)$ & $7(3.7)$ \\
\hline
\end{tabular}

$\mathrm{AD} / \mathrm{MCI}=$ Alzheimer's disease/mild cognitive impairment; $\mathrm{ALS}=$ amyotrophic lateral sclerosis; $\mathrm{FTD}=$ frontotemporal dementia; $M A P T=$ microtubuleassociated protein tau gene; ONDRI = Ontario Neurodegenerative Disease Research Initiative; PD = Parkinson's disease; VCI= vascular cognitive impairment.

did not display significant associations with PSP presentation. In addition, there were no significant associations between MAPT and any of the other FTD subtypes.

\section{DISCUSSION}

This is the first genetic characterization of the ONDRI cohort, which is important for upcoming multimodal, multi-year, prospective observational studies of the five phenotypes (e.g., $A P O E / M A P T$-based stratification). The principal findings from the current study are as follows: (1) a dose-dependent association of the APOE E4 allele with $\mathrm{AD}$ and an association between $\mathrm{E} 4$ and $\mathrm{MCI},(2)$ an inverse association of the $A P O E \mathrm{E} 2$ allele with $\mathrm{AD}$ and MCI presentation, (3) a lack of associations between the $A P O E$ alleles and other neurodegenerative diseases included in the ONDRI mandate (i.e. ALS, FTD, PD, or VCI), and (4) no associations between any of the five neurodegenerative disease cohorts and the MAPT H1 haplotype, but a significant association between $\mathrm{H} 1$ and the PSP subtype of FTD.

Our study design offers a unique opportunity to analyze individuals with one of five neurodegenerative diseases enrolled with strict inclusion criteria and evaluated across a wide range of platforms. ${ }^{27}$ Because of this robust workflow, we can investigate the effect of the $A P O E$ alleles and genotypes and MAPT haplotypes across multiple diseases with common assessment. The control cohort had a significantly older mean age than the ONDRI disease cohorts, as well as a significantly different male: female ratio. For this reason, logistic regression was applied to obtain ORs adjusted for both the age and sex of participants.

The E4 allele frequency in previously reported $\mathrm{AD}$ patients is $28-37 \%$, while in controls it is $8-14 \%$. $^{12,34}$ The results presented here are comparable to these literature values, with E4 allele frequencies of $31.7 \%$ and $14.5 \%$ in the $\mathrm{AD} / \mathrm{MCI}$ and control cohorts, respectively. More specifically, we observed an $A P O E$ E4 allele frequency of $46.3 \%$ in individuals with $\mathrm{AD}$ and $24.7 \%$ in individuals with MCI. Although the E4 allele frequency was significantly increased in cohorts of MCI compared to controls, the increase is not as great as that seen in those with AD only. Interestingly, the $\mathrm{E} 4$ allele has been shown to be a predictive risk factor for the clinical conversion from MCI to $\mathrm{AD},{ }^{35-37}$ which, coupled with the increased E4 allele frequency in the MCI subcohort, may indicate that a portion of the individuals enrolled in ONDRI with MCI will experience disease progression to AD. The longitudinal nature of the ONDRI study will permit followup of the individuals with MCI to determine whether their APOE status predicts possible progression to $\mathrm{AD}$ and to evaluate the phenotypic measures most severely affected by their status.

In accordance with previous literature, ${ }^{9}$ we identified that $A P O E \mathrm{E} 4$ was associated with $\mathrm{AD}$ in a dose-dependent manner following adjustment for age and sex. The presence of the E4 allele produced an approximately five-fold increased risk of having $\mathrm{AD} / \mathrm{MCI}$, which was marginally greater than the estimates previously found. However, we identified the E4/4 genotype to increase risk just over 10-fold, marginally lower than the commonly reported 12-fold. ${ }^{9,10}$ The slight discrepancies are likely due to the modest number of individuals enrolled in ONDRI with AD.

Previous studies have also suggested that the E2 allele decreases the risk of $\mathrm{AD}$, which we also observed with our $\mathrm{AD} / \mathrm{MCI}$ cohort. ${ }^{12,38}$ It is hypothesized that the stability provided by the cysteine-to-arginine variant at amino acid 176 may be contributing to this protective effect ${ }^{39}$ and allows the isoform to more effectively clear amyloid- $\beta,{ }^{40}$ protect against synaptic degeneration, ${ }^{41}$ and facilitate antioxidant activity. ${ }^{42}$ However, because of the small sample sizes within ONDRI, no individuals in the $\mathrm{AD} / \mathrm{MCI}$ cohort harbored the E2/2 genotype, and precise genotypic risk associations could not be evaluated. Despite the absence of individuals with the E2/2 genotype in the AD/MCI cohort, it is expected that two copies of the E2 allele would incrementally decrease the risk of the disease in a dose-dependent manner, particularly in those with $\mathrm{AD}$, but larger cohorts would be needed to validate this hypothesis.

Although an association was not observed between MAPT H1 and the total FTD cohort, we did observe an association between the haplotype and increased presentation of PSP, as has been previously identified. ${ }^{26}$ Yet, we were not able to replicate the previously observed increased prevalence of PSP associated with the $\mathrm{H} 1 \mathrm{H} 1$ diplotype, again possibly as a result of the modest number of individuals with PSP. Interestingly, the SD subcohort of FTD displayed the highest MAPT H1 haplotype frequency and 
the same $\mathrm{H} 1 \mathrm{H} 1$ diplotype frequency as the PSP subcohort but was not significantly associated with $M A P T$. We expect that the very low number of individuals enrolled in ONDRI with SD may be the driving factor in the lack of association observed here and believe that further analysis into the association between MAPT $\mathrm{H} 1$ and SD is warranted with larger sample sizes.

Due to the strong association between both the E4 allele and E4/4 genotype and AD status, many studies have attempted to identify associations with other neurodegenerative disorders. ${ }^{43}$ However, these studies reported inconsistent results regarding the risk associated with $A P O E \mathrm{E} 4$ and onset and/or progression of the other four diseases studied in ONDRI, namely, ALS, ${ }^{13,14}$ FTD $,{ }^{15,16} \mathrm{PD},{ }^{17-19}$ and VCI. ${ }^{20-22}$ Within the ONDRI cohort, no associations were identified for the other disease phenotypes. Similarly, no associations were identified between the MAPT H1 haplotype or $\mathrm{H} 1 / \mathrm{H} 1$ diplotype and any of the five complete neurodegenerative disease cohorts. Absence of associations could have been due to small sample sizes, and thus false negative inferences, or to the true lack of a biological effect of E4 and H1 in these conditions. Associations previously reported may have been due to the diagnostic challenges associated with neurodegenerative diseases. Admixture of $\mathrm{AD}$ pathology in individuals with other neurodegenerative diseases may produce false positive associations with E4, and copathologies within neurodegenerative diseases are far more common than previously appreciated. ${ }^{44}$ Due to the spectrum of overlapping features that can be observed across neurodegenerative phenotypes, it will be important to identify those that are associated with the APOE E4 allele and $M A P T \mathrm{H} 1$ haplotype to better understand patient prognosis. Future analyses will utilize ONDRI's robust assessment of structural and cognitive measures to identify whether common phenotypes across the various diseases are influenced by $A P O E$ and $M A P T$.

While ONDRI is unique in terms of the number of different clinical conditions evaluated simultaneously within the process, there is still a limitation due to modest sample sizes. Larger cohorts may produce results that align more closely with those previously reported. Additionally, an important limitation to this study is the lack of correlation with cognitive status within the disease cohorts. Assessments of cognitive impairment are ongoing, and future studies will incorporate these measures from the participants in order to assess the effects of the APOE E4 allele and MAPT haplotype on cognitive status within all five disease cohorts.

In conclusion, E4 allele carriers in the ONDRI study displayed a dose-dependent increased risk of $\mathrm{AD} / \mathrm{MCI}$, specifically in those diagnosed with $\mathrm{AD}$, which is consistent with the current $A P O E$ literature. Similarly, this study was concordant with recent evidence that the $A P O E \mathrm{E} 2$ allele decreases the risk of $\mathrm{AD} / \mathrm{MCI}$. Further, the MAPT H1 haplotype was significantly associated with the PSP subtype of FTD. The work also confirmed that risks of the other four diseases evaluated within ONDRI, namely, ALS, FTD, PD, and VCI are not associated with the E4 allele or E4/4 genotype and that none of the complete neurodegenerative disease cohorts are associated with the MAPT $\mathrm{H} 1$ haplotype or $\mathrm{H} 1 / \mathrm{H} 1$ diplotype. To our knowledge, this is the first study to analyze $A P O E$ genotypes and MAPT haplotypes across these five neurodegenerative diseases using common enrollment criteria and comprehensive phenotypic analysis. Future studies will investigate the structural and cognitive symptoms of neurodegeneration influenced by the E4 allele and $\mathrm{H} 1$ haplotype and the contributions of other genetic factors to these phenotypes.

\section{ACKNOWLEDGMENTS}

We would like to thank all ONDRI participants for their consent and cooperation with our study. Thank you to the ONDRI investigators (www.ONDRI.ca/people), and the ONDRI governing committees: the executive committee, steering committee, publication committee, recruiting committee, assessment platforms, and project management team. We also thank the London Regional Genomics Centre for their technical expertise. AAD is supported by the Alzheimer Society of London and Middlesex Doctoral Graduate Research Scholarship. SMKF is supported by the ALS Canada Tim E. Noël Postdoctoral Fellowship. MF receives support from the Saul A. Silverman Family Foundation as a Canada International Scientific Exchange Program and the Morris Kerzner Memorial Fund.

\section{FUNDING}

This work is funded by the Ontario Neurodegenerative Disease Research Initiative, through the Ontario Brain Institute, an independent nonprofit corporation, funded partially by the Ontario government. The opinions, results, and conclusions are those of the authors and no endorsement by the Ontario Brain Institute is intended or should be inferred.

\section{Disclosures}

Dr. Masellis reports grants from Canadian Institutes of Health Research, during the conduct of the study; other from Associate Editor, Current Pharmacogenomics and Personalized Medicine, personal fees from Bioscape Medical Imaging CRO, personal fees from GE Healthcare, personal fees from UCB, grants from Canadian Institutes of Health Research, grants from Early Researcher Award, Ministry of Economic Development and Innovation of Ontario, grants from Ontario Brain Institute, grants from Sunnybrook AFP Innovation Fund, grants from Alzheimer's Drug Discovery Foundation (ADDF), grants from Brain Canada, grants from Heart and Stroke Foundation Centre for Stroke Recovery, grants from Weston Brain Institute, personal fees from Novartis, personal fees from Henry Stewart Talks, other from Novartis, grants from Roche, grants from Washington University, grants from Teva, other from Teva, outside the submitted work. Outside the submitted work, Dr. Black reports institutional grants from GE Healthcare, Eli Lilly, Biogen Idec, Novartis, Genentech, Optina, Roche, and personal fees from Pfizer, Eli Lilly, Novartis, Merck, Medscape, Roche and Biogen Idec. Dr. Freedman reports grants from Ontario Brain Institute, during the conduct of the study. In addition, Dr. Freedman has a patent "Systems and methods for non-invasive biomarker assessment of dementia" pending. Dr. Lang reports personal fees from AbbVie, personal fees from Acorda, personal fees from BristolMyers Squib, personal fees from Biogen, personal fees from Merck, personal fees from Sun Pharma, personal fees from Corticobasal Solutions, personal fees from Sunovion, personal fees from Paladin, personal fees from Medichem, personal fees from Medtronic, outside the submitted work. Dr. Shoesmith reports grants from Ontario Brain Institute, during the conduct 
of the study. Dr. Swartz reports personal fees from The Ontario Brain Institute, during the conduct of the study.

\section{STATEMENT OF AUTHORSHIP}

All authors have approved this manuscript.

\section{REFERENCES}

1. Nalls MA, Pankratz N, Lill CM, et al. Large-scale meta-analysis of genome-wide association data identifies six new risk loci for Parkinson's disease. Nat Genet. 2014;46(9):989-93.

2. Lambert JC, Ibrahim-Verbaas CA, Harold D, et al. Meta-analysis of 74,046 individuals identifies 11 new susceptibility loci for Alzheimer's disease. Nat Genet. 2013;45(12):1452-8.

3. Simon-Sanchez J, Schulte C, Bras JM, et al. Genome-wide association study reveals genetic risk underlying Parkinson's disease. Nat Genet. 2009;41(12):1308-12.

4. Bertram L, McQueen MB, Mullin K, Blacker D, Tanzi RE. Systematic meta-analyses of Alzheimer disease genetic association studies: the AlzGene database. Nat Genet. 2007;39(1):17-23.

5. Mahley RW, Rall SC, Jr. Apolipoprotein E: far more than a lipid transport protein. Annu Rev Genomics Hum Genet. 2000;1: 507-37.

6. Kane JW, Gowland E. A method for the identification of apolipoprotein $\mathrm{E}$ isoforms employing chemical precipitation and flat bed isoelectric focusing in agarose. Ann Clin Biochem. 1986;23 (Pt 5):509-13.

7. Zannis VI, Breslow JL, Utermann G, et al. Proposed nomenclature of apoE isoproteins, apoE genotypes, and phenotypes. J Lipid Res. 1982;23(6):911-4.

8. Ward A, Crean S, Mercaldi CJ, et al. Prevalence of apolipoprotein E4 genotype and homozygotes (APOE e4/4) among patients diagnosed with Alzheimer's disease: a systematic review and meta-analysis. Neuroepidemiology. 2012;38(1):1-17.

9. Corder EH, Saunders AM, Strittmatter WJ, et al. Gene dose of apolipoprotein E type 4 allele and the risk of Alzheimer's disease in late onset families. Science. 1993;261(5123):921-3.

10. Saunders AM, Strittmatter WJ, Schmechel D, et al. Association of apolipoprotein $\mathrm{E}$ allele epsilon 4 with late-onset familial and sporadic Alzheimer's disease. Neurology. 1993;43(8):1467-72.

11. Liu Y, Yu JT, Wang HF, et al. APOE genotype and neuroimaging markers of Alzheimer's disease: systematic review and metaanalysis. J Neurol Neurosurg Psychiatry. 2015;86(2):127-34.

12. Farrer LA, Cupples LA, Haines JL, et al. Effects of age, sex, and ethnicity on the association between apolipoprotein E genotype and Alzheimer disease. A meta-analysis. APOE and Alzheimer Disease Meta Analysis Consortium. JAMA. 1997;278(16):1349-56.

13. Mui S, Rebeck GW, McKenna-Yasek D, Hyman BT, Brown RH, Jr. Apolipoprotein E epsilon 4 allele is not associated with earlier age at onset in amyotrophic lateral sclerosis. Ann Neurol. 1995; 38(3):460-3.

14. Li YJ, Pericak-Vance MA, Haines JL, et al. Apolipoprotein E is associated with age at onset of amyotrophic lateral sclerosis. Neurogenetics. 2004;5(4):209-13.

15. Agosta F, Vossel KA, Miller BL, et al. Apolipoprotein E epsilon4 is associated with disease-specific effects on brain atrophy in Alzheimer's disease and frontotemporal dementia. Proc Natl Acad Sci USA. 2009;106(6):2018-22.

16. Geschwind D, Karrim J, Nelson SF, Miller B. The apolipoprotein E epsilon4 allele is not a significant risk factor for frontotemporal dementia. Ann Neurol. 1998;44(1):134-8.

17. Ezquerra M, Campdelacreu J, Gaig C, et al. Lack of association of APOE and tau polymorphisms with dementia in Parkinson's disease. Neurosci Lett. 2008;448(1):20-3.

18. Pankratz N, Byder L, Halter C, et al. Presence of an APOE4 allele results in significantly earlier onset of Parkinson's disease and a higher risk with dementia. Mov Disord. 2006;21(1):45-9.

19. Huang X, Chen PC, Poole C. APOE-[epsilon]2 allele associated with higher prevalence of sporadic Parkinson disease. Neurology. 2004;62(12):2198-202.
20. Baum L, Lam LC, Kwok T, et al. Apolipoprotein E epsilon4 allele is associated with vascular dementia. Dement Geriatr Cogn Disord. 2006;22(4):301-5.

21. Davidson Y, Gibbons L, Purandare N, et al. Apolipoprotein E epsilon4 allele frequency in vascular dementia. Dement Geriatr Cogn Disord. 2006;22(1):15-9.

22. Chuang YF, Hayden KM, Norton MC, et al. Association between APOE epsilon4 allele and vascular dementia: The Cache County study. Dement Geriatr Cogn Disord. 2010;29(3):248-53.

23. Myers AJ, Kaleem M, Marlowe L, et al. The H1c haplotype at the MAPT locus is associated with Alzheimer's disease. Hum Mol Genet. 2005;14(16):2399-404.

24. Seto-Salvia N, Clarimon J, Pagonabarraga J, et al. Dementia risk in Parkinson disease: disentangling the role of MAPT haplotypes. Arch Neurol. 2011;68(3):359-64.

25. Ferrari R, Wang Y, Vandrovcova J, et al. Genetic architecture of sporadic frontotemporal dementia and overlap with Alzheimer's and Parkinson's diseases. J Neurol Neurosurg Psychiatry. 2017;88(2):152-64.

26. Baker M, Litvan I, Houlden $\mathrm{H}$, et al. Association of an extended haplotype in the tau gene with progressive supranuclear palsy. Hum Mol Genet. 1999;8(4):711-5.

27. Farhan SM, Bartha R, Black SE, et al. The Ontario Neurodegenerative Disease Research Initiative (ONDRI). Can J Neurol Sci. 2017;44(2):196-202.

28. Farhan SMK, Dilliott AA, Ghani G, et al. The ONDRISeq panel: custom-designed next-generation sequencing of genes related to neurodegeneration. NPJ Genom Med. 2016(16032):1-11.

29. Li H, Wetten S, Li L, et al. Candidate single-nucleotide polymorphisms from a genomewide association study of Alzheimer disease. Arch Neurol. 2008;65(1):45-53.

30. Dilliott AA, Farhan SMK, Ghani M, et al. Targeted Nextgeneration Sequencing and Bioinformatics Pipeline to Evaluate Genetic Determinants of Constitutional Disease. J Vis Exp. 2018(134)

31. Wang K, Li M, Hakonarson H. ANNOVAR: functional annotation of genetic variants from high-throughput sequencing data. Nucleic Acids Res. 2010;38(16):e164.

32. Koch W, Ehrenhaft A, Griesser K, et al. TaqMan systems for genotyping of disease-related polymorphisms present in the gene encoding apolipoprotein E. Clin Chem Lab Med. 2002; 40(11):1123-31.

33. Lai MC, Bechy AL, Denk F, et al. Haplotype-specific MAPT exon 3 expression regulated by common intronic polymorphisms associated with Parkinsonian disorders. Mol Neurodegener. 2017; 12(1):79.

34. Heffernan AL, Chidgey C, Peng P, Masters CL, Roberts BR. The Neurobiology and Age-Related Prevalence of the epsilon4 Allele of Apolipoprotein E in Alzheimer's Disease Cohorts. J Mol Neurosci. 2016;60(3):316-24.

35. Elcoroaristizabal Martin X, Fernandez Martinez M, Galdos Alcelay L, et al. Progression from amnesic mild cognitive impairment to Alzheimer's disease: ESR1 and ESR2 polymorphisms and APOE gene. Dement Geriatr Cogn Disord. 2011;32(5):332-41.

36. Petersen RC, Thomas RG, Grundman M, et al. Vitamin E and donepezil for the treatment of mild cognitive impairment. N Engl J Med. 2005;352(23):2379-88.

37. Fleisher AS, Sowell BB, Taylor C, Gamst AC, Petersen RC, Thal LJ. Clinical predictors of progression to Alzheimer disease in amnestic mild cognitive impairment. Neurology. 2007;68(19): 1588-95.

38. Corder EH, Saunders AM, Risch NJ, et al. Protective effect of apolipoprotein $\mathrm{E}$ type 2 allele for late onset Alzheimer disease. Nat Genet. 1994;7(2):180-4.

39. Zhong N, Weisgraber KH. Understanding the association of apolipoprotein E4 with Alzheimer disease: clues from its structure. J Biol Chem. 2009;284(10):6027-31.

40. Yang DS, Smith JD, Zhou Z, Gandy SE, Martins RN. Characterization of the binding of amyloid-beta peptide to cell culture-derived native apolipoprotein E2, E3, and E4 isoforms and to isoforms from human plasma. J Neurochem. 1997;68(2):721-5. 
41. Dumanis SB, Tesoriero JA, Babus LW, et al. ApoE4 decreases spine density and dendritic complexity in cortical neurons in vivo. J Neurosci. 2009;29(48):15317-22.

42. Miyata M, Smith JD. Apolipoprotein E allele-specific antioxidant activity and effects on cytotoxicity by oxidative insults and betaamyloid peptides. Nat Genet. 1996;14(1):55-61.
43. Verghese PB, Castellano JM, Holtzman DM. Apolipoprotein E in Alzheimer's disease and other neurological disorders. Lancet Neurol. 2011;10(3):241-52.

44. Robinson JL, Lee EB, Xie SX, et al. Neurodegenerative disease concomitant proteinopathies are prevalent, age-related and APOE4-associated. Brain. 2018;141(7):2181-93. 